these underhand methods, but what can one do?" Similarly, Miller points out that Chandra continued to complain bitterly that leading physicists never supported him against Eddington, despite the fact that Paul Dirac, Rudolf Peierls and Maurice Price wrote an important paper that backed him up.

On the sidewalks of the narration, one also picks up some interesting snippets, such as how the Nobel laureate Raman declared that there will be no astrophysicists within miles of Bangalore; or how Chandra decided to spend some time in America because of the "underhanded dealings going on in Indian scientific circles"; and why Robert Oppenheimer had a successful collaboration with Richard Tolman.

In summary, this is an entertaining and illuminating book about a key issue in contemporary astrophysics. The author is to be congratulated on producing an authoritative description in a manner that is so thoroughly enthralling.

Thanu Padmanabhan is at Pune University, Ganeshkhind, Pune 411 007, India.

\section{Destroying the zombic hunch}

\section{Sweet Dreams: Philosophical \\ Obstacles to a Science of \\ Consciousness}

by Daniel C. Dennett

MIT Press: 2005. 216 pp, \$28, £18.95

\section{Susan Blackmore}

Has the devil lost his horns? Dan Dennett has been demonized because of his tough materialist stance on consciousness and his claim that we are conscious machines with nobody at home inside. But now he updates his theory and, I think, presents a softer version of it.

Sweet Dreams is a collection of essays and lectures written between 1999 and 2005 in which Dennett tries to freeze time and present a 'best' version of his evolving ideas. There are problems with this, especially as some chunks are somewhat disconcertingly repeated from one chapter to the next, but the overall picture gives a good idea of where Dennett's thinking has been going.

He describes his task as being to explain away qualia-based intuitive objections to materialism, and this he does using some of his favourite examples. One is the everpopular philosopher's zombie, an imaginary creature who looks, acts and speaks like a normal person but has no subjective

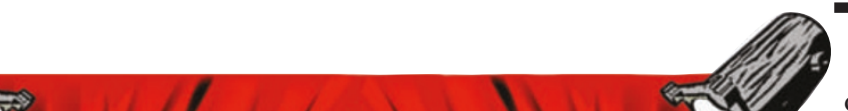

watching the magic show of conscious experiences from the safety of the cartesian theatre. Dennett contrasts those theorists to whom it is obvious that a theory that leaves out the subject cannot explain consciousness, with those to whom it is obvious that the subject has to vanish. The first type must be wrong, he says: "A good theory of consciousness should make a conscious mind look like an abandoned factory."

All these ideas will be familiar to lovers and haters of Dennett, as will his attacks on Mary the colour-scientist (who knows all there is to know about colour perception but lives in a black-and-white world) and the idea of first-person science. But he does add some new twists and, as ever, delights with his quirky turns of phrase. I laughed out loud at his example of a folk theorem as ludicrous as some of the ones that people claim are obvious: "If you burp, sneeze, and fart all at the same time, you die." But let's have some evidence, he says.

What may be less familiar is Dennett's updating of his theory of consciousness, from the original 'multiple drafts' theory, through the delightfully named 'fantasy echo', to his latest ideas of 'fame in the brain' or 'cerebral celebrity'.

In a paper originally published as an overview for a special 2001 issue of Cognition, he joins in the experience or qualia. It's easy to imagine a zombie — or at least to think you are imagining one - says Dennett, and he calls this "falling for the zombic hunch", which traps people into believing that consciousness is separate from brain function. Dennett has tried to murder the zombie before, explaining how people fail to follow the rules when they think they are imagining one, but now with the concept of the zombic hunch he explores the damage done by this false intuition. Don't worry, he says, if you are patient and open minded it will pass, or mutate into a less virulent form. Just as we still feel as though the Earth stands still, in the future people may still feel the zombic hunch, but they won't believe it. They will know that mechanistic theories of consciousness do the whole job, so we don't need the concept of qualia.

Demystifying consciousness is Dennett's forte, and is probably the main reason for his status as the devil - after all, people like mysteries. Some even think that if consciousness is explained they will be diminished as people, being turned into mere 'things'. They don't like the idea that there is no one at home inside their head, no audience "gathering consensus" that favours 'global workspace' theory. Originally proposed by Bernard Baars in A Cognitive Theory of Consciousness (Cambridge University Press, 1988), this theory is explicitly based on a theatre metaphor in which the contents of consciousness are illuminated by a spotlight of attention, shining on the stage of working memory. The idea is that many specialist brain systems contribute information to the global workspace; its contents are then broadcast to the rest of the system and this global availability is experienced as a conscious state.

Doesn't this go against everything Dennett has been fighting for? He tries to explain why not. Consciousness, like fame, is not an intrinsic property of brain processes but is more like political influence or clout; conscious events are the ones that have widespread effects in the brain. So we must not think that becoming famous in the brain magically ignites the glow of conscious qualia or lets pictures into the cartesian theatre to be watched by the conscious subject; the effects are enough. Fame in the brain does not lead to consciousness - it is consciousness. 
Many global-workspace theorists don't see it this way, and Dennett says they are "surrendering just when victory is at hand". The critical point hinges on what he calls the 'hard question': "And then what happens?". (This is not to be confused with Chalmers' 'hard problem', which Dennett thinks is illusory.) If you think that something has to happen next, such as entering consciousness or becoming conscious, then you are still wallowing in mystery.

But if the devil had stuck with his original multiple-drafts theory, he would surely have gone further. One of its most startling claims,

\section{Making progress?}

FAB: The Coming Revolution on Your Desktop - From Personal Computers to Personal Fabrication by Neil Gershenfeld

Basic Books: 2005. 288 pp. \$26, £19.99

\section{Don Ihde}

What happens to the notion of 'revolution' when it occurs every day, month or year? I suspect it comes to mean the same as 'normal' - or it becomes irritating, as constant changes end up preventing planned action.

The rhetorical cast of $F A B$ is one of technofantasy and wild projection, which strangely recalls some equally extravagant medieval theological puzzles. "Can God create a stone that is too heavy for him to lift?" is paralleled here by another puzzle: can we humans build a machine that could then make a machine better than itself? This technofantasy opens $F A B$, which stands for personal fabrication: a programmable personal fabricator will be able "to make anything, including itself, by assembling its atoms. It will be a self-reproducing machine."

But, at least the author, Neil Gershenfeld - former director of the Media Lab at Massachusetts Institute of Technology (MIT) and now director of its Center for Bits and Atoms - recognizes this as a "long-standing science-fiction staple". Boundless enthusiasm and boys-and-toys utopianism seem to be the tradition, and I had a hard time overcoming my own scepticism in order to get to a more sober assessment of what is happening.

The book arose from a popular course at MIT, "How To Make (Almost) Anything", taught by Gershenfeld. It draws many students from diverse backgrounds, all enthusiastic to build, or 'personally fabricate', things. From the second chapter on, we get descriptions of some of these objects. ScreamBody is a sort of fuzzy soundproofed knapsack into which the user screams, but passers-by cannot hear; it contains a recording device that can then later be played and, with the bag open, be heard by others. Another is a web browser designed for use by parrots, made by Dennett in Consciousness Explained (Little, Brown, 1991), is that "there are no fixed facts about consciousness independent of particular probes". I took this to mean something like this: at any time there are multiple versions of representations in the brain, none of which is conscious or unconscious. Only when the system is probed - for example by asking a question or requiring an action - does one of the drafts have consequences that cause us to say, after the fact, that it was conscious. In other words, there are no conscious and unconscious streams; nothing ever 'enters consciousness'; there

who seem to like their new toy. Yet another is an alarm clock that you have to wrestle with to turn off, stopping you slipping back to sleep. These are indeed imaginative fabrications.

It seems that the heart of this operation is a network of new hook-ups, connecting different tools and processors to programmed computer assistance: computer-assisted design, computer-assisted manufacture, computer-assisted cutting... If you imagine a desktop computer that is hooked up not to a two-dimensional printer but to a threedimensional product producer, you've got the idea.

The trajectory that dominates FAB is the production of many types of 'Hello World' artefacts. Hello World, the standard test for computer languages, can be printed out by any desktop computer hooked up to a printer, but when hooked up to engraving devices it can be printed as a bas-relief, cut out as independent letters (hooked up to a laser cutter) or even in heavy material (using a supersonic water cutter).

But you could use the same water cutter to produce polycarbonate plastic bicycle frames of any design, as they do on the MIT course. The other bicycle parts are off the shelf, and when assembled the various designs could then be seen on the streets of Cambridge. I can see why this class is fun, and as a bricolage inventor myself from my Kansas childhood - my brother and I welded together a bale loader from our father's junk pile - I can begin to catch the infectious enthusiasm that permeates FAB. Yet I can't shake the doubts: what is the revolutionary future of using a US\$100,000 water cutter to make polycarbonate bicycle frames? At $\$ 20,000$ for Fab Labs exported to the Third World, the process seems rather expensive.

What is infectious, and possibly of some revolutionary importance, is the way in which Fab Labs have been exported and prepared for use by children and distant, Third World is no "crucial finish line or boundary somewhere in the brain, marking a place where the order of arrival equals the order of 'presentation' in experience".

Yet the global-workspace theorists believe in conscious and unconscious streams, in contents becoming conscious, and in looking for the neural correlates of the 'movie in the brain'. I think they still need the old devil.

Susan Blackmore is a freelance writer, lecturer and broadcaster, and a visiting lecturer at the University of the West of England, Bristol, UK.
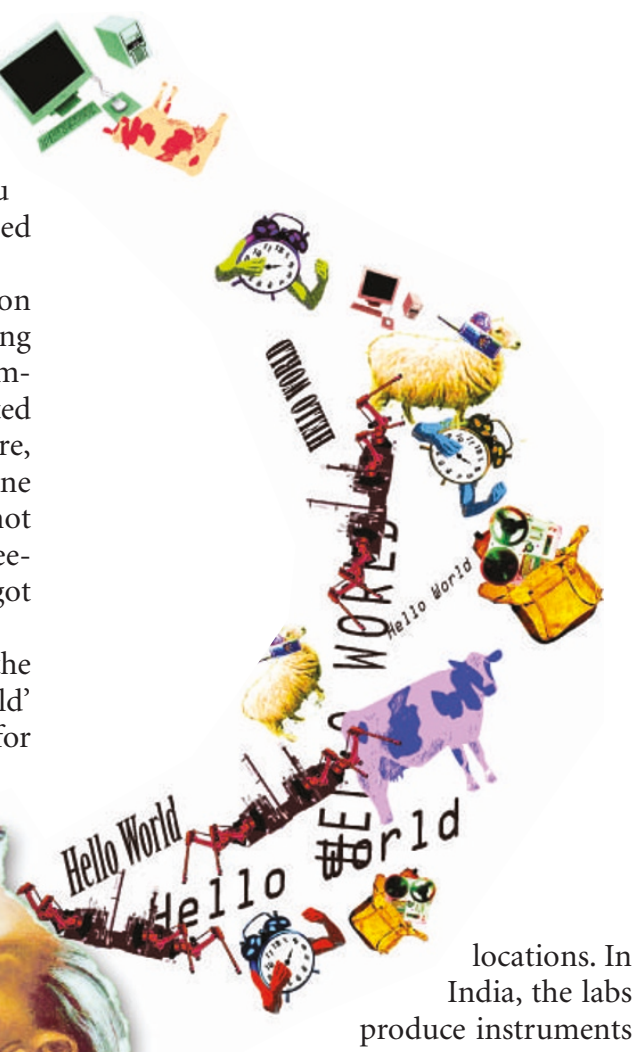

that can measure fat and milk/cream ratios in milk, which villagers can then use to good effect. In Norway, transmitters have been developed to help herders locate their sheep, and they have been transformed into local networks for communication as well. Children from a slum learned to program their own lab, on a computer placed in a hole in the wall, often with innovations never dreamed of by the designers.

It strikes me that the 'revolution' that emerges is that of self-learned skills through playing with Fab Labs. Desktops hooked up to various new connections, flexible enough for eight-year-olds to invent things, in effect democratize this technical development. Such technological multistability, of course, remains unpredictable. And so much often begins in play. That is the possibility created by Fab Labs. "Imagination au pouvoir" was, after all, the slogan of the revolutionary Days of May in 1968 Paris.

Don Ihde is in the Department of Philosophy,

Stony Brook University, New York 11794, USA. 